\title{
RELATIONSHIP BETWEEN VITAMIN A DEFICIENCY AND PNEUMONIA INCIDENCE OF CHILDREN UNDER FIVE YEARS OF AGE IN WEST JAVA
}

\author{
Magdalena Gultom, Ririn Arminsih Wulandari \\ Master Program of Public Health, Universitas Indonesia \\ Faculty of Public Health, Universitas Indonesia
}

\begin{abstract}
Background: The leading cause of mortality in children under five years of age is acute lower respiratory tract infections, especially bronchiolitis and pneumonia. Vitamin A supplement has been studied as a potential intervention to decrease severity and prevent acute lower respiratory tract infections from subsequent episodes. This study aimed to determine the relationship between vitamin A deficiency and pneumonia incidence of children under five years of age in West Java.

Subjects and Method: A cross-sectional study was conducted using the secondary data from Indonesian Demographic and Health Survey, 2017 in West Java. A sample of 594 toddlers under 5 years of age was obtained for this study. The dependent variable was pneumonia. The independent variable was vitamin A intake. The data were collected using questionnaires. The data were analyzed by chi-square.

Results: As many as 38.6\% children under five years of age did not get vitamin A supplement. $26.8 \%$ of children suffered pneumonia. Inadequate vitamin A intake increased the risk of pneumonia in children under five years of age $(\mathrm{OR}=1.011,95 \% \mathrm{CI} 0.690$ to $1.481 ; \mathrm{p}=1.000)$.

Conclusion: Inadequate vitamin A intake increases the risk of pneumonia in children under five years of age, but it is not statistically significant.
\end{abstract}

Keywords: vitamin A deficiency, pneumonia, prevention, under five years of age, children

Correspondence:

Magdalena Gultom. Masters Program in Public Health, Faculty of Public Health, Universitas

Indonesia, Depok, West Java. Email: magdalena.gultomui@gmail.com. Mobile: +6281299714873 . 